\title{
Pre-existing Antibody: Biotherapeutic Modality-Based Review
}

\author{
Boris Gorovits, ${ }^{1,11}$ (D) Adrienne Clements-Egan, ${ }^{2}$ Mary Birchler, ${ }^{3}$ Meina Liang, ${ }^{4}$ Heather Myler, ${ }^{5}$ Kun Peng, ${ }^{6}$ \\ Shobha Purushothama, ${ }^{7}$ Manoj Rajadhyaksha, ${ }^{8}$ Laura Salazar-Fontana, ${ }^{9}$ Crystal Sung, ${ }^{10}$ and Li Xue ${ }^{1}$
}

Received 9 December 2015; accepted 20 January 2016; published online 28 January 2016

\begin{abstract}
Pre-existing antibodies to biotherapeutic drugs have been detected in drug-naïve subjects for a variety of biotherapeutic modalities. Pre-existing antibodies are immunoglobulins that are either specific or cross-reacting with a protein or glycan epitopes on a biotherapeutic compound. Although the exact cause for pre-existing antibodies is often unknown, environmental exposures to non-human proteins, glycans, and structurally similar products are frequently proposed as factors. Clinical consequences of the pre-existing antibodies vary from an adverse effect on patient safety to no impact at all and remain highly dependent on the biotherapeutic drug modality and therapeutic indication. As such, pre-existing antibodies are viewed as an immunogenicity risk factor requiring a careful evaluation. Herein, the relationships between biotherapeutic modalities to the nature, prevalence, and clinical consequences of pre-existing antibodies are reviewed. Initial evidence for pre-existing antibody is often identified during anti-drug antibody (ADA) assay development. Other interfering factors known to cause false ADA positive signal, including circulating multimeric drug target, rheumatoid factors, and heterophilic antibodies, are discussed.
\end{abstract}

KEYWORDS: anti-drug antibody; immunogenicity; pre-existing antibody.

\section{INTRODUCTION}

The appearance of anti-drug antibodies (ADAs) is considered a risk to patient safety, and therefore, ADAs are routinely monitored during clinical trials. Antibodies that cross-react with a biotherapeutic drug are often observed during the immunogenicity assessments of samples collected from treatment-naïve subjects (1-3). These pre-existing antibodies (pre-Abs) can be defined as endogenous antibodies that are specific or reactive for domains of proteins or

${ }^{1}$ Pfizer Worldwide Research \& Development, PDM, 1 Burtt Rd, Andover, MA, USA.

${ }^{2}$ Janssen Research \& Development, LLC (Johnson \& Johnson), Welsh and McKean Roads, Spring House, PA, USA.

${ }^{3}$ Clinical Immunology, GlaxoSmithKline, King of Prussia, PA, USA.

${ }^{4}$ MedImmune, Clinical Pharmacology and DMPK, Mountain View, CA, USA.

${ }^{5}$ Bristol-Myers Squibb, Analytical \& Bioanalytical Development, Princeton, NJ, USA.

${ }^{6}$ Genentech, BioAnalytical Sciences, San Francisco, CA, USA.

${ }^{7}$ UCB Celltech, Slough, UK.

${ }^{8}$ Regeneron Pharmaceuticals, Inc. Bioanalytical Sciences, Tarrytown, NY, USA.

${ }^{9}$ DSAR, Project Standards and Innovation, Immunology and Biomarkers, Sanofi R\&D, Framingham, MA, USA.

${ }^{10}$ DSAR, Clinical Laboratory Sciences, Sanofi R\&D, Framingham, MA, USA.

${ }^{11}$ To whom correspondence should be addressed. (e-mail: boris.gorovits@pfizer.com) glycans that overlap with biotherapeutic epitopes. They can either be components of the natural antibody population of the host, a part of the innate immune system, or components of the adaptive immune responses to environmental antigens or a homologous biotherapeutic. To ascertain the likelihood of a clinical consequence of ADAs, it may be important to screen for pre- $\mathrm{Ab}$ responses and characterize them sufficiently to derive a good overall risk assessment of ADA formation (4).

Pre-Abs may affect PK, efficacy, or safety of biotherapeutics $(5,6)$. Patients who are positive for pre-Ab and undergo therapy may subsequently experience an adverse clinical event due to hypersensitivity reactions (7-9). Pre-Abs have been associated with a post-treatment loss of product efficacy and adverse safety consequences (10), as observed with enzyme therapy, TNF-alpha inhibitors, and interferons (11-15). Other cases have shown no clinical impact (16). Specificity of pre-Abs can range from simple carbohydrates to larger epitopes, including some neo-epitopes that may be generated in a fusion protein (17). Plant-produced biotherapeutics and vaccines may contain plant glycan motifs from plant allergens, though the exact consequence of plant glycan specific pre-Abs is still debated (18).

Pre-Abs also may confound the assessment of immunogenicity testing results by causing interference in an ADA assay and impacting ADA assay cut-point value. Thus, it is critical to distinguish pre-Abs from other pre-existing reactivity, which can also lead to a positive assay signal.

Although pre- $\mathrm{Ab}$ responses pose an immunogenicity risk, it is difficult to know whether existence of pre-Abs can 
promote treatment-boosted ADAs and lead to clinical adverse events (19). This manuscript provides a review of the nature of various pre-existing anti-drug antibodies reported for a wide variety of biotherapeutic modalities. Other assay interfering factors that may constitute preexisting reactivity are also discussed.

This manuscript was written as part of a broader effort by the American Association of Pharmaceutical Scientists (AAPS) Therapeutic Protein Immunogenicity and Ligand Binding Assay Bioanalytical Focus Groups (TPIFG and LBABFG) to summarize industry experiences and practices related to analysis, characterization, and mitigation of preexisting antibodies to biotherapeutics.

\section{NATURE AND CHARACTERIZATION OF PRE-EXISTING REACTIVITY IN ADA ASSAYS}

Various interfering factors are frequently detected during initial steps of ADA assay development. Matrix components that are present in drug-naïve samples and capable of generating ADA like signals may be referred to as preexisting reactivity. Pre-existing reactivity is heterogeneous by nature and is comprised of various types of matrix components including those that facilitate drug intermolecular interactions (19-21). Below are some examples of matrix components that could cause pre-existing reactivity in ADA assays:

- Pre-existing antibodies (pre-Abs): Antibodies reactive with the biologic drug that are present in subjects before treatment (or before initiation of the clinical study) (22). These are naturally occurring or otherwise endogenous antibodies to a variety of proteins and glycans that cross react with drug-specific epitopes. Biotherapeutic modality specific pre-Abs are described in other sections of this review.

- Drug-specific interfering factors: Endogenous proteins or other substances found in naïve biological fluids specifically binding to the drug, for example, soluble multimeric drug target, proteins binding to the drug based on its mode of action, etc.

- Non-specific interferants: Rheumatoid factors (RF) and other heterophilic antibodies with a potential to interact with either the drug or the assay reagent components (e.g., human anti-animal antibodies $(23,24)$ ).

The use of certain assay platforms, formats, and reagents may accentuate the impact of assay interference and result in a signal that appears as ADA-positive reactivity in the ADA assay $(21,25,26)$. As an example, a multimeric soluble drug target can effectively bind to the reagents in a bridge format ADA assay resulting in generation of a false-positive ADA read out $(21,27)$. Interference may occur due to multi-valent IgM RF or drug-binding heterophilic antibodies. Even small changes in conserved wild-type sequence may result in elevated RF binding (28). ADA assay analytical platforms often require use of chemically modified protein reagents, which can alter the protein structure, aggregation state, and specificity (29). For example, electrochemiluminescence (ECL) readout bridge format ADA assays utilize biotinylated and ruthenium $(\mathrm{Ru}++)$-labeled drug. Low levels of aggregates present in the assay reagent have been shown to cause false-positive ADA-like signals (25).

To assess and reduce assay interference, analysis of individual drug naïve matrix samples is a critical step during ADA assay development (30). If a significant irrelevant background signal is observed in the drug-naïve population, various mitigation strategies can be applied including sample pre-treatment aiming to remove or block matrix interference or a modification to the assay platform or components $(20,26)$. Specialized reagents have been used to block interfering factors and prevent them from binding to ADA assay reagents (26-28). This includes use of protein A, G, L, anti-human IgM, or an Fc truncated reagent to address interference of $\mathrm{RF}$ and heterophilic antibodies (31). Understanding of the exact nature of matrix interference appears to be critical to determine whether there is any evidence of true pre-existing antidrug antibodies and avoid removal of drug specific ADA during sample pre-treatment step.

Reasons for the presence of drug specific endogenous pre-Abs vary greatly. The exact cause is often unknown but could be an outcome of prior exposure to a protein or glycan with a similar epitope. Examples include prior environmental exposure to non-human proteins (32) or glycans not commonly expressed on human proteins (9) or previous treatment by a structurally similar product as part of a switch between alternative biologic regimens $(4,33,34)$. Post-translational modifications of biotherapeutics produced in non-human cell lines may result in generation of glycans uncommon to humans with known antibody specificity. Antibodies specific to various non-human glycans have been broadly reported (Table I) and recently reviewed by Karin et al (14). Anti-Gal- $\alpha-1,3-G a l-s p e c i f i c$ immunoglobulins are naturally present in normal humans at high titers although only the presence of $\mathrm{IgE}$ isotype was correlated with allergic reactions to meat or Cetuximab ${ }^{\mathrm{TM}}$, a biotherapeutic that contains the Gal- $\alpha-1,3-\mathrm{Gal}$ on its Fab region $(35,36)$. Antibodies specific to $\mathrm{N}$-glycolylneuraminic acid, a glycan generated by non-human cell lines, are reported to comprise up to $0.1-0.2 \%$ of circulating $\operatorname{IgG}$ in normal humans (37). Antibodies specific to other glycans have been associated with adult and pediatric Crohn's disease progression (38-41) (Table I).

Current drug-specific antibody detection methods are designed to report samples as ADA positive or negative based on comparison with the assay specific cut-point value. The cut-point value is commonly defined based on statistical analysis of assay signals generated using drug naïve samples from study specific population (30). Pre-Abpositive drug-naive samples can impact this procedure. For example, anti-diphtheria toxin (DT) Ab was found in up to $80 \%$ of normal human sera (42). Exclusion of data from pre-Ab positive samples was required to avoid generation of an inappropriately high cut-point value and to reduce risk of false-negative reporting (43). No standard recommendation exists for the most appropriate approach to determine an ADA assay cut-point value when a high prevalence of pre-Abs is observed.

In the following sections, herein, we review information on pre-Abs for various biotherapeutic modalities and their consequences. 
Table I. Examples of Glycans with Known Naturally Occurring Antibody Specificity in Humans

\begin{tabular}{|c|c|c|}
\hline Glycan & Specificity and occurrence & Ref \\
\hline $\begin{array}{l}\text { Galactose- } \alpha-1,3 \text {-galactose (Gala1-3Galb1-4GlcNAc-R, } \\
\text { Gal- } \alpha-1,3-\text { Gal epitope) }\end{array}$ & $\begin{array}{l}\text { Common antigen present on many animal and bacteria proteins. } \\
\text { Anti- Gal- } \alpha-1,3-\text { Gal antibodies occur naturally in majority of humans }\end{array}$ & $(35,36)$ \\
\hline $\begin{array}{l}\text { N-Glycolylneuraminic acid (Neu5Gc, } \\
\text { non-human sialic acid) }\end{array}$ & $\begin{array}{l}\text { Variable amounts are found in humans with a potential to form immune } \\
\text { complexes and impact drug PK }\end{array}$ & $(37)$ \\
\hline $\begin{array}{l}\beta(1,2) \text {-Xylose } \\
\alpha(1,3) \text {-Fucose }\end{array}$ & IgEs with specificity to glycans was associated with plant allergens & $(38)$ \\
\hline Mannobioside $(\operatorname{Man}(\alpha-1,3)$ Mana $)$ & Associated with Crohn's disease & $(39,40)$ \\
\hline $\begin{array}{l}\text { Laminaribioside }(\operatorname{Glc}(\beta-1,3) \operatorname{Glc}(\beta)) \\
\text { Chitobioside }(\operatorname{GlcNAc}(\beta-1,4) \operatorname{GlcNAc}(\beta))\end{array}$ & & \\
\hline $\begin{array}{l}\text { Gal- } \beta-1-3-\text { GalNAc- } \alpha \\
\text { GalNAc- } \alpha\end{array}$ & Tumor-associated antigens & $(41)$ \\
\hline
\end{tabular}

\section{MONOCLONAL ANTIBODIES AND ANTIBODY FRAGMENTS}

Since the first regulatory approval of a murine antibody for therapeutic use in humans (44), mAbs and their derivatives have become important modalities of therapeutic potential. Progress from murine to fully human molecules has generally led to reduced immunogenicity, as human antianimal antibodies, most commonly anti-mouse, are present in up to $80 \%$ of humans (23). In the case of Infliximab ${ }^{\mathrm{TM}}$, a chimeric anti-TNF antibody, higher levels of pre-existing Fab reactive $\mathrm{IgG}$ were associated with reduced long-term efficacy in inflammatory bowel disease (IBD) patients (45). Advances in antibody engineering and $\mathrm{mAb}$ production techniques have enabled development of mAbs with tailored PK and pharmacological properties although possibly introduced additional immunogenicity related challenges. A recent AAPS survey reported the prevalence of pre-Abs to be up to $3.8 \%$ in clinical studies with humanized IgG1 mAbs (46). The prevalence of pre-Abs reactive with novel antibody scaffolds was reported to be up to $41.7 \%$, although the rheumatoid arthritis (RA) population included in these studies may have been a significant contributing factor for this increased prevalence (46).

The importance of the therapeutic mAb allotype for the potential ADA reactivity in the clinic has been suggested based on the presence of serologically defined allotypes in various populations (47). A monoclonal antibody of a given allotype delivered to a cohort of patients homozygous for the alternative allotype may lead to potential immunogenicity reactions. Pre-existing anti-G1m1 antibodies were seen in 2 G1m3 homozygous healthy subjects administered a fulllength humanized aglycosylated IgG1 expressing two heavy chains of the G1m17,1 allotype (48). A possible association between frequency of anti-Adalimumab ${ }^{\text {TM }}$ ADA responses and Adalimumab $^{\mathrm{TM}}$ allotype $(\mathrm{G} 1 \mathrm{~m}, 17)$ vs. the allotype of patients treated with Adalimumab ${ }^{\text {TM }}$ showed lack of association potentially due to either the minor antigenicity of the G1m allotype or inability of the ADA assay to detect low abundance responses (49).

Endogenous antibodies specific to antibody fragments, but not to an intact immunoglobulin are well known. Endogenous antibodies in rabbits recognizing immunoglobulin fragments created by proteolytic cleavage were first described almost 50 years ago (50). Similar endogenous antibodies have been discovered in humans, and the repertoire in the literature is growing. Cleavage of antibodies in the hinge region results in the formation of either Fab (upper hinge cleavage) or $\mathrm{F}(\mathrm{ab}$ ')2 (lower hinge cleavage) fragments. The site of cleavage varies depending on the protease, and thus antibodies of differing specificities have been found (51). The biological relevance of these antibodies is not fully understood. In the case of Abciximab $^{\mathrm{TM}}$, a chimeric Fab fragment targeting the GPIIb/IIIa integrin and generated by papain treatment of $\mathrm{IgG}$, interaction with such antibodies was associated with acute thrombocytopenia (52). Although the prevalence of these autoantibodies was high (74\%), thrombocytopenia was seen in only $1-2 \%$ of patients. Pre-Abs to an anti-TNFR1 heavy chain domain antibody fragment were found in approximately $50 \%$ of drug naïve healthy human subjects (53). These antibodies did not cross-react with larger antibody fragments or full $\mathrm{mAb}$, suggesting that, as in the case of anti-hinge autoantibodies, they recognized a cryptic epitope exposed after the cleavage. In this case, antibody/ drug complexes were shown to cross-link and activate the TNFR1 receptor, leading to symptoms of cytokine release. In the case of TAS266, a tetravalent Nanobody ${ }^{\text {TM }}$ targeting the DR5 receptor, pre-Abs were seen in three of the four subjects dosed. In this case, liver toxicity was seen in antibody-positive subjects (54). This may be the result of immune complexes binding to the DR5 receptor on hepatocytes, leading to apoptosis. In both of these instances, the negative biological effect of the pre-Abs was target dependent. Overall, pre-Abs to $\mathrm{mAbs}$ and their fragments have been primarily reported where modifications or alterations to the protein structure are introduced.

\section{PEGYLATED BIOLOGIC PROTEINS}

PEG is generally considered to be a non-toxic and nonimmunogenic polymer, commonly used in the production of cosmetics, toothpaste, foods, and drinks, and is approved by FDA as a constituent of various medicines and medical procedures $(55,56)$. Covalent attachment of polyethylene glycol (PEG) to a protein is an approach commonly used to improve drug stability and pharmacokinetic properties. The expected benefits relating to the protein Pegylation ${ }^{\mathrm{TM}}$ are increased product half- life in circulation, inhibition of renal filtration and reduced immunogenicity (57-59). PEGylated biologics have been developed for various indications. 
Several pegylated biologics that have received regulatory approval include PegIntron ${ }^{\mathrm{TM}}$ (pegylated interferon-alpha 2b), Pegasys ${ }^{\text {тм }}$ (pegylated interferon-alpha 2) Neulasta $^{\text {тм }}$ (pegylated granulocyte colony stimulating factor), Mircera ${ }^{\text {TM }}$ (methoxy polyethylene glycol-epoetin beta), and Oncaspar ${ }^{\mathrm{TM}}$ (pegylated L-asparaginase derived from E. coli).

Given the wide nature of PEG exposure, PEG specific antibodies are frequently reported. Initially, the prevalence of anti-PEG antibodies was determined as $0.2 \%$ in healthy subjects and $3.3 \%$ in untreated allergic patients (60). Later, with the implementation of advanced analytical assay platforms and increased exposure of the population, higher and variable estimates of anti-PEG antibody prevalence were reported ranging from $7.5 \%$ in systemic lupus erythematous patients (16) to $22-25 \%$ in healthy donors (61) and $44 \%$ in hepatitis C patients (16). Another report describes 10\% prevalence of anti-PEG pre-Abs in healthy individuals, hepatitis B and hepatitis C donor sera (62). Reported differences in prevalence values are likely due to specific properties of the assays used for the assessments of ADA, along with differences in patient and sample characteristics.

The impact of anti-PEG pre-Abs present in drug naive patients is not well understood. In the case of PEGylated interferon, a high prevalence of anti-PEG pre-Abs was not associated with impaired response to PEG-interferon in hepatitis $\mathrm{C}$ patients (16). In the case of Pegloticase ${ }^{\text {тм }}$, a recombinant pegylated porcine uricase, low titer predominately $\operatorname{IgM}$ isotype pre-Abs with presumed antiPEG specificity were detected in $15 \%$ of patients and did not predict subsequent impact on the drug effect (63). In a separate study, pre-existing anti-Pegloticase ${ }^{\mathrm{TM}}$ antibodies with specificity to the PEG moiety found in $19 \%$ of drug-naïve patients partially contributed to the increased clearance and reduced efficacy of the drug (64).

Overall, the prevalence and impact of the anti-PEG preAbs varies with specific products and study populations (16,62-66) (Table II). High incidences of treatment induced anti-PEG antibodies have been documented only for the large conjugates of highly immunogenic proteins, such as Pegloticase $^{\mathrm{TM}}$ (Table II). It is unclear if the size of the PEG conjugates affect the detection of anti-PEG pre-Abs and possibly contribute to an increased immunogenicity incidence thus limiting therapeutic efficacy in patients. In addition, the potential risk of anti-PEG pre-Abs to cause epitope spreading and thereby an enhanced antibody response to the protein portion of the PEG conjugates remains to be determined.

\section{ANTIBODY DRUG CONJUGATES}

Antibody drug conjugates (ADCs) are a class of biotherapeutics containing more than one domain each with a specific function: a monoclonal antibody specific to a tumor antigen and a cytotoxic or cytostatic small molecular weight toxin (payload) attached via a linker (67). Immune response to the ADCs could be elicited against the monoclonal antibody, the linker-payload or the linker. Antibodies against the monoclonal antibody moiety of the ADC could impact efficacy by blocking target binding, whereas antibody against the linker-payload or the payload could cause off-target toxicity by enhancing uptake of the cytotoxin into non-target

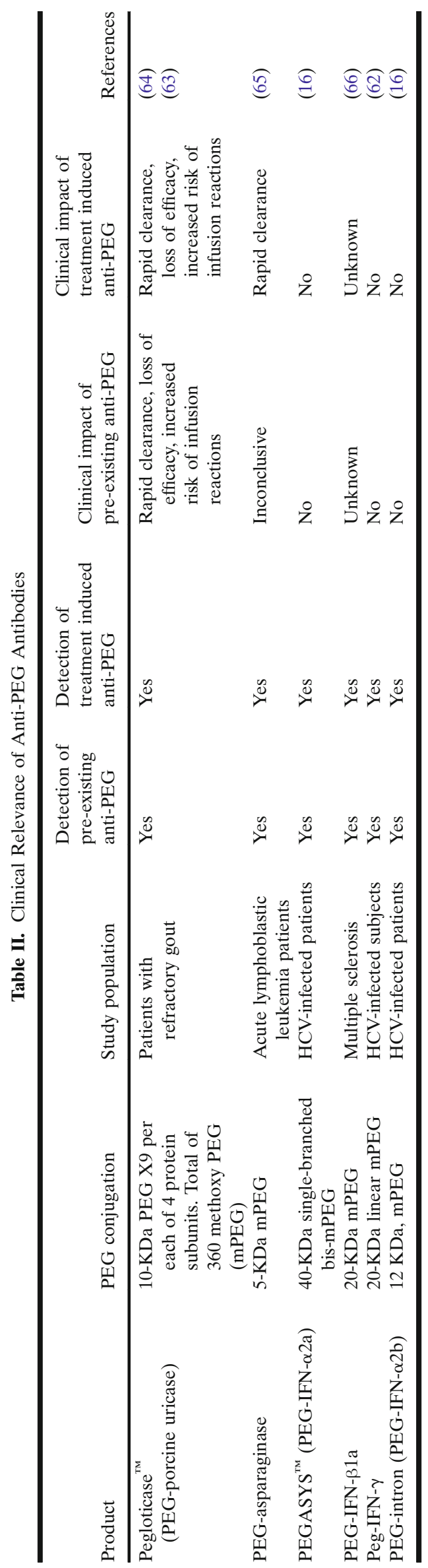


cells, particularly in organs involved in immune complex clearance, such as the liver and spleen (68). In addition, immune responses against the payload could preclude use of other therapies containing the same payload.

Pre-Abs specific to methyl glycoside moiety on calicheamicin toxin, derived from bacterium Micromonospora echinospora (69), have been reported in naïve human serum (70). In the case of ado-Trastuzumab Emtansine (T-DM1 ${ }^{\mathrm{TM}}$, Kadcyla $^{\mathrm{TM}}$ ) most treated patients had received prior treatment with Trastuzumab $^{\mathrm{TM}}$ (TmAb), the protein component of TDM1 (71). A confirmed positive baseline sample in a $\mathrm{T}$ $\mathrm{DM}^{\mathrm{TM}}$ study could indicate presence of pre-existing anti$\mathrm{TmAb} A D A$-induced during previous TmAb treatment. In six clinical studies, 13 patients were confirmed positive (signal depleted by $\mathrm{T}-\mathrm{DM} 1^{\mathrm{TM}}$ ) at baseline (71). However, the overall prevalence of the pre-Abs was within the $1 \%$ expected falsepositive rate for the confirmatory assay with no reported impact on safety or efficacy of T-DM $1^{\mathrm{TM}}$ due to TmAb specific pre-Abs. At this time, the clinical significance of anti-TDM1 ${ }^{\mathrm{TM}}$ antibodies is unknown (72).

The dearth in published literature about the impact of pre-Abs on safety and efficacy of ADCs could be due to: (i) ADC therapies are administered to immune suppressed cancer patients where the immunogenicity risk is usually low and (ii) limited data available to date: there are three approved ADCs in the USA, with one subsequently withdrawn from the market.

\section{IMMUNOTOXINS}

Immunotoxins are a class of targeted biotherapeutics that are fusion proteins composed of a cell-binding domain and a toxin moiety (73). As of today, denileukin difitox $\left(\right.$ Ontak $\left.^{\mathrm{TM}}\right)$, an immunotoxin composed of interleukin-2 and truncated DT, was approved for the treatment of cutaneous T cell lymphoma (74). Although immunotoxins demonstrated a promise as anti-cancer therapy in clinical trials, they have not become a standard treatment largely due to their immunogenicity potentials. The toxin part of these molecules could elicit antibody responses in humans due to the presence of nonhuman sequences. If humans have prior exposure to the toxin either due to infection or vaccination (42), toxin-specific preAbs could develop and potentially impact safety and efficacy of immunotoxin therapy.

Understanding of the specificity of anti-DT pre-Abs has proven to be valuable for the design of immunotoxins. In an in vitro study with human serum samples, which demonstrated detectable anti-DT Abs even in the absence of evidence of prior immunization, anti-DT Abs completely neutralized the cell-killing activity of anti-CD3-full-length DT immunotoxin, while only moderately inhibited the activity of an anti-CD3-C-terminal truncated DT immunotoxin (42). The result suggested that the C-terminus of DT contains dominant epitopes recognized by anti-DT pre-Abs. A study in monkeys was consistent with these findings (75) as it demonstrated that anti-DT pre-Abs, likely present due to prior infection, did not impact the $\mathrm{T}$ cell depletion activity of an anti-CD3-truncated DT immunotoxin. Anti-CD3-full-length DT immunotoxin was less efficacious in animals positive for anti-DT pre-Abs as compared to pre-Ab negative animals. These observations led to a hypothesis that truncated DT could be a potential solution to bypass the neutralizing effect of pre-existing antiDT Ab, which was confirmed in humans. Clinical trial results demonstrated that presence of anti-DT pre-Abs has no significant impact on the clinical efficacy of several immunotoxins containing truncated DT as the percentage of individuals with detectable baseline anti-DT antibody levels was comparable in responders and non-responders (76) $\left(\right.$ Ontak $^{\mathrm{TM}}$ and A- dmDT 390 -bisFv (UCHT1)).

\section{CYTOKINES, PEPTIDES, GROWTH FACTORS}

Cytokines include a broad category of small proteins, approximately $5-20 \mathrm{kDa}$, that are produced by a range of immune cells and play an important role in modulating humoral and cell-based immune responses and other regulatory pathways. Recombinant cytokines being used as therapeutics are included in Table III. Watanabe et al. 2010 provide a thorough review of examples of cytokine specific autoantibodies as primary causes of disease by neutralizing endogenous cytokine activity, as exacerbating factors of disease by augmenting cytokine signal transduction, as attenuating factors of disease severity, and those that are induced by viral infection or tumor burden (77). For example, presence of anti-IL-1 antibody has been inversely correlated with disease severity in patients with RA (78).

In a clinical trial comparing the safety and efficacy of peginterferon Lambda/Ribavirin ${ }^{{ }^{T M}}(\mathrm{RBV})$ or peginterferon Lambda/RBV/Daclatasvir $^{\mathrm{TM}}$ (DCV) with Alfa (Pegasys ${ }^{\mathrm{TM}}$ )/ RBV co-administration naïve chronic Hepatitis $C$ virus GT2,3 infected patients were tested for pre-Abs specific to PEG-interferon (IFN) lambda (or alpha, depending on the treatment arm) antibodies, and for a post-therapy change in ADA titers (62). In the PEG-IFN lambda treatment arm, 9\% of subjects had pre-Abs of which $17 \%$ had a 5 or greater postdose increase in ADA titer (boosting event) compare to $31.5 \%$ incidence in pre-Ab negative patients. It is unclear if these pre-existing antibodies were primarily against the PEG moiety or the IFN as patient status on pre-Abs specific to PEG, IFN lambda or IFN alpha were not included in the enrollment exclusionary criteria. The exact impact of ADA in this study is still under evaluation although it appeared that pre-Abs had negligible impact on patient outcome.

In a separate study, samples from chronic hepatitis Binfected $\mathrm{HBeAg}^{+}$subjects who had no prior exposure to IFN were analyzed for pre-Abs and post-therapy ADA boosting to PEG and IFN lambda or IFN alpha (depending on the treatment regimen). As described by Myler et al (62), the prevalence of anti-PEG pre-Abs $(6 \%)$ and anti-INF pre-Abs $(10 \%)$ were similar with limited evidence of ADA boosting post-treatment.

In understanding the immunogenicity risk of pre-Abs for a given cytokine-based therapy, it is important to note that cytokines can be both redundant and pleiotropic. While multiple lines of evidence support the notion that cytokine specific autoantibodies may be present and ubiquitous in healthy individuals (79), their potential physiological role is less clear. It is hypothesized that they may function by scavenging pro-inflammatory cytokines and inhibiting deleterious "endocrine" effects, or by serving as carrier proteins, providing a "reservoir" of inactive cytokines (77). These mechanisms should be clearly outlined in a prospective 
Table III. Recombinant Cytokines Approved by the FDA as of 2014

\begin{tabular}{ll}
\hline Biotherapeutic & Indication \\
\hline Bone morphogenic protein (BMP) & Bone growth \\
Erythropoietin (EPO) & Anemia \\
Granulocyte colony-stimulating factor (G-CSF) & Neutropenia \\
Granulocyte macrophage colony-stimulating factor (GM-CSF) & Neutropenia and fungal infections \\
Interferon alpha & Hepatitis C and multiple sclerosis \\
Interferon beta & Multiple sclerosis \\
Interleukin 2 (IL-2) & Malignant melanoma, renal cell cancer \\
Interleukin 11 (IL-11) & Thrombocytopenia \\
Interferon gamma & Chronic granulomatous disease and osteoporosis \\
\hline
\end{tabular}

immunogenicity risk assessment with plans for mitigation, i.e., tolerance induction, patient exclusion, real-time monitoring of boosting as deemed needed to preserve patient safety and improve therapeutic efficacy.

\section{PROTEIN REPLACEMENT THERAPIES}

Enzyme replacement therapies (ERT) are used to treat patients with enzyme deficiency or insufficiency. The objective of enzyme replacement therapy is to achieve an adequate in vivo level of enzyme in patients with diseases such as lysosomal storage disorders (LSD) (Gaucher, Fabry, MPS I, MPS II, MPS VI, and Pompe) (11). Immune induction to ERT has been widely reported (80-82). Reported impact of treatment induced immune responses for LSD has ranged from no alarming effect $(83,84)$ to hypersensitivity/ anaphylactic reactions (11) to sustained high antibody titers that correlated with poor clinical outcomes in the case of Pompe disease $(80,81)$.

Limited information is published about pre-Abs and their impact on ERT. Pre-Abs in LSD patients generally are attributed to prior exposure to other structurally similar lysosomal proteins (34) or mutated endogenous enzymes. The potential impact of pre-Abs is the removal of the lysosomal protein from circulation $(11,12)$.

Pompe disease $(\alpha$-glucosidase deficiency, glycogen storage disease type II) is an example of LSD condition. Typical treatment for Pompe disease is the administration of recombinant human (rh) GAA (Myozyme ${ }^{\mathrm{TM}}$ and Lumizyme $^{\mathrm{TM}}$ ). In an infantile Pompe disease study, limited number of patients had low level of baseline anti-GAA antibodies. Evidence of pre-existing anti-GAA antibody did not correlate with adverse effects or otherwise impact on clinical outcome of the treatment (82).

In another case study for mucopolysaccharidosis I ( $\alpha$-Liduronidase deficiency) therapy, all patients (10 in total) enrolled had low background levels of anti- $\alpha$-L-iduronidase pre-Abs as detected by the epitope mapping ELISA which was explained by possible exposure to the endogenous protein or existence of cross-reacting epitopes on related proteins such as plant and microbial glycosidases with structural similarities (12). After once weekly intravenous infusions of $\mathrm{rh} \alpha$-L-iduronidase, 5 of the 10 patients showed a treatment induced antibody response, however by week 104, all patients were back to the baseline levels indicating immune tolerance to the ERT (12). The impact of pre-Abs on the clinical outcome following treatment was not described.

Autoantibodies to coagulation factors have been reported in cases of acquired deficiencies of factor VIII, von Wilebrand factor, and factor XIII (85). These autoantibodies are pathologically acquired immunoglobulins that are able to neutralize the activation or function of a specific clotting factor (85). Low titer autoantibodies to Factor VIII found in some healthy individuals have no reported clinical significance and belong to all IgG subclasses. Similar autoantibodies against factor VIII found in autoimmune disease patients mainly belong to IgG1 and IgG4 (85). The significance of apparent $\mathrm{IgG}$ subclass difference as well as impact of autoantibodies on the replacement therapy are not clear (85). Many factors including study population (previously treated versus previously untreated), study design, ADA assay sensitivity, ADA sampling frequency, and duration of follow-up contribute to the lack of a proper understanding of the impact. No publications could be identified that describe direct investigations of the impact of pre-Abs on previously treated patients when they are undergoing a product switch.

\section{GENE THERAPY}

Gene therapy approaches have been applied as candidate therapies for several disorders including hemophilia B, Parkinson, age-related macular degeneration, and artery disease (86-88). Gene therapy utilizes virus (such as adenovirus, adeno-associated virus (AAV), lentivirus) vectors which carry a transgene of interest to the host cells. In general, the prevalence of anti-viral vector antibodies depends upon the type of viral vector and viral serotype. Pre-Abs to viral vectors can impact the efficacy and potential safety of gene therapy. The presence of neutralizing pre-Ab (NAb) against viral capsid proteins can block entry of the agents into targeted cells and preclude successful gene expression.

The efficacy of gene transfer by adenovirus transfection has to date been limited. For example, the intramuscular injection in the skeletal muscle of patients leads to short duration of gene expression (88). In contrast, lentiviral vectors have recently gained increasing attention due to their ability of stable Integration into the genome of targeted cells and the absence of pre-Abs against vector components in most humans. The major drawback of the lentiviral vector is its capability to produce replication-competent viral vectors, which would potentially induce insertional mutagenesis in the patient (89). 
In recent years, AAV vectors have been considered as highly promising for the in vivo gene delivery because of the lack of human pathogenicity, long-term gene expression, and ability to efficiently transduce dividing and non-dividing cells. However, pre-Abs to AAV proteins remain a major challenge (90). Pre-Abs to wild-type AAV2 virus capsid component have been associated with a rapid elimination of the transduced viruses in a phase I study of hemophilia B treatment (91). Natural AAV infections in humans and nonhuman primates established a broad range of antibody responses to related viruses. Anti-AAV antibody can be detected as early as at birth, suggesting vertical transmission of maternal antibodies. Several studies suggest that prevalence of anti-AAVs antibody depends on the viral serotype and geography. A worldwide epidemiology study of NAbs specific to AAVs revealed that the anti-AAV2 antibodies were the most prevalent across different regions, followed by antibodies to AAV1 than to AAV7 and AAV8 (92). Previous studies reported prevalence of antibodies to AAV1 and AAV2 serotypes in human to range from 30 to $80 \%(93,94)$. Prevalence of anti-AAV2 NAbs was reported to be approximately $40 \%$ in a newborn population (95) and from 23 to $49 \%$ in adult human sera samples, depending on the assay cutoff value used (96).

An AAV8 non-human primate study demonstrated a significant decrease in gene transfer and transgene expression rates for animals with pre-existing NAb titers above 1/10 (96). A phase I/II clinical study using AAV1 gene transfer in patients with advanced heart failure showed lack of improvement in patients with pre-existing anti-AAV1 NAb $(n=2)$ in contrast to some improvements in NAb negative patients $(n=7)$ (97).

Adenoviral and AAV-based gene transfer vectors have been developed for vaccines against several diseases including HIV-1 infection. An HIV vaccine study with human adenovirus serotype 5 (Ad5) as a viral vector showed that treated subjects with pre-existing NAb to the Ad5 had an unexpected increase in the acquisition of HIV infection as compared to placebo control subjects (98). A recent study showed that the majority of healthy and HIV-1 infected individuals in China were positive for NAbs to AAV2 and AAV8. Seroprevalence was much higher for AAV2 (>90\%) and AAV8 (>82\%) than for AAV5 (40\%) in healthy individuals in China (99) suggesting that the AAV5 vector may be more appropriate for human gene therapy or vaccine development.

It may be concluded that it is important to determine a clinical threshold of anti-AAV NAb against a specific viral serotype to stratify patient population in order to increase the probability of therapeutic efficacy. Several additional approaches have been proposed to overcome pre-existing $\mathrm{NAb}$ challenge including plasmapheresis and saline flushing prior to vector administration, immune suppression, and development of NAb-resistant AAV constructs (90).

\section{SUMMARY}

There is a growing evidence of a broad range and nature of pre-exiting drug-specific antibodies with varying specificities toward protein, glycan, or other types of epitopes on biotherapeutic compounds. The exact origin of the pre- existing antibodies is frequently not known but often is a result of an environmental exposure, prior experience with structurally similar products, non-human proteins, or glycans. Causes for pre-existing antibodies to biologic drugs are often modality specific and may be accentuated by the nature of the treated disease population. Overall pre-existing antibodies are generally looked upon as a potential immunogenicity risk factor. The clinical impact of pre-existing antibodies also varies greatly. The industry as a whole continues to work toward understanding of the risks of pre-existing antibody existence, their impact on patient safety, compound efficacy, and immunogenicity potential.

\section{ACKNOWLEDGMENTS}

The authors would like to thank Alyssa Morimoto (Genentech) for her contribution to the manuscript outline. The authors also would like to acknowledge the AAPS Therapeutic Protein Immunogenicity and Ligand Binding Assay Bioanalytical Focus Groups for the support during the writing of this manuscript.

\section{REFERENCES}

1. Bendtzen K, Hansen MB, Ross C, Svenson M. High-avidity autoantibodies to cytokines. Immunol Today. 1998;19(5):209-11.

2. Sauerborn M, Schellekens H. B-1 cells and naturally occurring antibodies: influencing the immunogenicity of recombinant human therapeutic proteins? Curr Opin Biotechnol. 2009;20(6):715-21.

3. Soos JM, Polsky RM, Keegan SP, Bugelski P, Herzyk DJ. Identification of natural antibodies to interleukin-18 in the sera of normal humans and three nonhuman primate species. Clin Immunol. 2003;109(2):188-96.

4. Center for Drug Evaluation and Research (CDER), Center for Biologics Evaluation and Research (CBER). Guidance for Industry. Immunogenicity Assessment for Therapeutic Protein Products. U.S. Department of Health and Human Services Food and Drug Administration (FDA) 2013; Available from: http://www.fda.gov/ downloads/drugs/guidancecomplianceregulatoryinformation/guidances/ucm338856.pdf.

5. Ballard JL, Weaver FA, Singla NK, Chapman WC, Alexander WA. Safety and immunogenicity observations pooled from eight clinical trials of recombinant human thrombin. J Am Coll Surg. 2010;210(2):199-204. doi:10.1016/j.jamcollsurg.2009.09.042.

6. Matsuo T, Suzuki S, Matsuo M, Kobayasi H. Preexisting antibodies to platelet factor 4-heparin complexes in patients with acute coronary syndrome who have no history of heparin exposure. Pathophysiol Haemost Thromb. 2005;34(1):18-22. doi:10.1159/000088543.

7. Strullu M, Corradini N, Audrain M, Orsonneau JL, Bouige D, Thomare $\mathrm{P}$, et al. Silent hypersensitivity to Escherichia coli asparaginase in children with acute lymphoblastic leukemia. Leuk Lymphoma. 2010;51(8):1464-72. doi:10.3109/10428194.2010.494316.

8. Burke MJ. How to manage asparaginase hypersensitivity in acute lymphoblastic leukemia. Future Oncol (London, England). 2014;10(16):2615-27. doi:10.2217/fon.14.138.

9. Chung CH, Mirakhur B, Chan E, Le QT, Berlin J, Morse M, et al. Cetuximab-induced anaphylaxis and IgE specific for galactosealpha-1,3-galactose. N Engl J Med. 2008;358(11):1109-17.

10. Liu Y, Reidler H, Pan J, Milunic D, Qin D, Chen D, et al. A double antigen bridging immunogenicity ELISA for the detection of antibodies to polyethylene glycol polymers. J Pharmacol Toxicol Methods. 2011;64(3):238-45.

11. Brooks DA. Immune response to enzyme replacement therapy in lysosomal storage disorder patients and animal models. Mol Genet Metab. 1999;68(2):268-75. doi:10.1006/mgme.1999.2894. 
12. Kakavanos R, Turner CT, Hopwood JJ, Kakkis ED, Brooks DA. Immune tolerance after long-term enzyme-replacement therapy among patients who have mucopolysaccharidosis I. Lancet. 2003;361(9369):1608-13. doi:10.1016/s0140-6736(03)13311-9.

13. Khan OA, Dhib-Jalbut SS. Neutralizing antibodies to interferon beta-1a and interferon beta-1b in MS patients are cross-reactive. Neurology. 1998;51(6):1698-702.

14. van Schie KA, Wolbink GJ, Rispens T. Cross-reactive and preexisting antibodies to therapeutic antibodies-effects on treatment and immunogenicity. mAbs. 2015;7(4):662-71. doi:10.1080/ 19420862.2015.1048411.

15. Sorensen PS. Neutralizing antibodies against interferon-beta. Ther Adv Neurol Disord. 2008;1(2):62-78. doi:10.1177/ 1756285608095144.

16. Tillmann H, Ganson NJ, Patel K, Thompson AJ, Abdelmalek M, Moody T, et al. 307 High prevalence of pre-existing antibodies against polyethylene glycol (PEG) in hepatitis $\mathrm{C}(\mathrm{HCV})$ patients which is not associated with impaired response to PEGinterferon. J Hepatol. 2010;52:S129. doi:10.1016/S01688278(10)60309-1.

17. Miller LL, Korn EL, Stevens DS, Janik JE, Gause BL, Kopp WC, et al. Abrogation of the hematological and biological activities of the interleukin-3/granulocyte-macrophage colonystimulating factor fusion protein PIXY321 by neutralizing antiPIXY321 antibodies in cancer patients receiving high-dose carboplatin. Blood. 1999;93(10):3250-8.

18. Ward BJ, Landry N, Trepanier S, Mercier G, Dargis M, Couture $\mathrm{M}$, et al. Human antibody response to $\mathrm{N}$-glycans present on plant-made influenza virus-like particle (VLP) vaccines. Vaccine. 2014;32(46):6098-106. doi:10.1016/j.vaccine.2014.08.079.

19. Xue L, Fiscella M, Rajadhyaksha M, Goyal J, Holland C, Gorovits B, et al. Pre-existing biotherapeutic-reactive antibodies: survey results within the American Association of Pharmaceutical Scientists. AAPS J. 2013;15(3):852-5.

20. Gorovits B, McNally J, Fiorotti C, Leung S. Protein-based matrix interferences in ligand-binding assays. Bioanalysis. 2014;6(8):1131-40. doi:10.4155/bio.14.56.

21. Chen K, Page JG, Schwartz AM, Lee TN, DeWall SL, Sikkema $\mathrm{DJ}$, et al. False-positive immunogenicity responses are caused by $\mathrm{CD} 20+\mathrm{B}$ cell membrane fragments in an anti-ofatumumab antibody bridging assay. J Immunol Methods. 2013;394(1-2):2231. doi:10.1016/j.jim.2013.04.011.

22. Shankar G, Arkin S, Cocea L, Devanarayan V, Kirshner S, Kromminga A, et al. Assessment and reporting of the clinical immunogenicity of therapeutic proteins and peptidesharmonized terminology and tactical recommendations. AAPS J. 2014;16(4):658-73. doi:10.1208/s12248-014-9599-2.

23. Kricka LJ. Human anti-animal antibody interferences in immunological assays. Clin Chem. 1999;45(7):942-56.

24. Bjerner J, Olsen KH, Bormer OP, Nustad K. Human heterophilic antibodies display specificity for murine IgG subclasses. Clin Biochem. 2005;38(5):465-72.

25. Tatarewicz S, Miller JM, Swanson SJ, Moxness MS.Rheumatoid factor interference in immunogenicity assays for human monoclonal antibody therapeutics J Immunol Methods. 2010;357(12):10-6. doi:10.1016/j.jim.2010.03.012.

26. Bautista AC, Wullner D, Moxness M, Swanson SJ, Chirmule N, Jawa V. Impact of matrix-associated soluble factors on the specificity of the immunogenicity assessment. Bioanalysis. 2010;2(4):721-31. doi:10.4155/bio.10.24.

27. Carrasco-Triguero M, Mahood C, Milojic-Blair M, Amaya C, Ruppel J, Hong $\mathrm{K}$, et al. Overcoming soluble target interference in an anti-therapeutic antibody screening assay for an antibody-drug conjugate therapeutic. Bioanalysis. 2012;4(16):2013-26.

28. Araujo J, Zocher M, Wallace K, Peng K, Fischer SK. Increased rheumatoid factor interference observed during immunogenicity assessment of an Fc-engineered therapeutic antibody. J Pharm Biomed Anal. 2011;55(5):1041-9. doi:10.1016/ j.jpba.2011.03.008.

29. O'Hara DM, Theobald V, Egan AC, Usansky J, Krishna M, TerWee J, et al. Ligand binding assays in the 21 st century laboratory: recommendations for characterization and supply of critical reagents. AAPS J. 2012;14(2):316-28. doi:10.1208/s12248012-9334-9.
30. Shankar G, Devanarayan V, Amaravadi L, Barrett YC, Bowsher $\mathrm{R}$, Finco-Kent D, et al. Recommendations for the validation of immunoassays used for detection of host antibodies against biotechnology products. J Pharm Biomed Anal. 2008;48(5):126781. doi:10.1016/j.jpba.2008.09.020.

31. Warren DJ, Bjerner J, Paus E, Bormer OP, Nustad K. Use of an in vivo biotinylated single-chain antibody as capture reagent in an immunometric assay to decrease the incidence of interference from heterophilic antibodies. Clin Chem. 2005;51(5):830-8. doi:10.1373/clinchem.2004.046979.

32. Xue L, Johnson R, Gorovits B. Prevalence and isotypic complexity of the anti-Chinese hamster ovary host cell protein antibodies in normal human serum. AAPS J. 2010;12(1):98-106. doi:10.1208/s12248-009-9165-5.

33. Matino D, Lillicrap D, Astermark J, Dolan G, Kessler C, Lambert T, et al. Switching clotting factor concentrates: considerations in estimating the risk of immunogenicity. Haemophilia : Off J World Fed Hemophilia. 2014;20(2):200-6. doi:10.1111/ hae.12283.

34. Glaros EN, Turner CT, Parkinson EJ, Hopwood JJ, Brooks DA. Immune response to enzyme replacement therapy: single epitope control of antigen distribution from circulation. Mol Genet Metab. 2002;77(1-2):127-35.

35. Galili U, Anaraki F, Thall A, Hill-Black C, Radic M. One percent of human circulating B lymphocytes are capable of producing the natural anti-Gal antibody. Blood. 1993;82(8):248593.

36. Arnold DF, Misbah SA. Cetuximab-induced anaphylaxis and IgE specific for galactose-alpha-1,3-galactose. N Engl J Med. 2008;358(25):2735-6.

37. Ghaderi D, Taylor RE, Padler-Karavani V, Diaz S, Varki A. Implications of the presence of $\mathrm{N}$-glycolylneuraminic acid in recombinant therapeutic glycoproteins. Nat Biotechnol. 2010;28(8):863-7. doi:10.1038/nbt.1651.

38. van Ree R, Cabanes-Macheteau M, Akkerdaas J, Milazzo JP, Loutelier-Bourhis C, Rayon C, et al. Beta(1,2)-xylose and alpha(1,3)-fucose residues have a strong contribution in IgE binding to plant glycoallergens. J Biol Chem. 2000;275(15):11451-8.

39. Dotan I, Fishman S, Dgani Y, Schwartz M, Karban A, Lerner A, et al. Antibodies against laminaribioside and chitobioside are novel serologic markers in Crohn's disease. Gastroenterology. 2006;131(2):366-78. doi:10.1053/j.gastro.2006.04.030.

40. Rieder F, Schleder S, Wolf A, Dirmeier A, Strauch U, Obermeier F, et al. Serum anti-glycan antibodies predict complicated Crohn's disease behavior: a cohort study. Inflamm Bowel Dis. 2010;16(8):1367-75. doi:10.1002/ibd.21179.

41. Springer GF. T and Tn, general carcinoma autoantigens. Science (New York, NY). 1984;224(4654):1198-206.

42. Thompson J, Hu H, Scharff J, Neville Jr DM. An anti-CD3 single-chain immunotoxin with a truncated diphtheria toxin avoids inhibition by pre-existing antibodies in human blood. $\mathrm{J}$ Biol Chem. 1995;270(47):28037-41.

43. Myler H, Felix T, Zhu J, Hruska M, Piccoli SP. Measuring biotherapeutics with endogenous counterparts and pre-existing antibodies: an interferon case study. Bioanalysis. 2014;6(8):111322.

44. Smith SL. Ten years of Orthoclone OKT3 (muromonab-CD3): a review. J Transpl Coord. 1996;6(3):109-19.

45. Steenholdt C, Palarasah Y, Bendtzen K, Teisner A, Brynskov J, Teisner B, Nielsen CH. Pre-existing IgG antibodies crossreacting with the Fab region of infliximab predict efficacy and safety of infliximab therapy in inflammatory bowel disease. Aliment Pharmacol Ther. 2013;37(12):1172-83. doi:10.1111/ apt.12330.

46. Xue L, Rup B. Evaluation of pre-existing antibody presence as a risk factor for posttreatment anti-drug antibody induction: analysis of human clinical study data for multiple biotherapeutics. AAPS J. 2013;15(3):893-6. doi:10.1208/s12248013-9497-z.

47. Jefferis R, Lefranc MP. Human immunoglobulin allotypes: possible implications for immunogenicity. mAbs. 2009;1(4):332-8.

48. Tatarewicz SM, Juan G, Swanson SJ, Moxness MS. Epitope characterization of pre-existing and developing antibodies to an 
aglycosylated monoclonal antibody therapeutic of G1m17,1 allotype. J Immunol Methods. 2012;382(1-2):93-100. doi:10.1016/j.jim.2012.05.009.

49. Bartelds GM, de Groot E, Nurmohamed MT, Hart MH, van Eede $\mathrm{PH}$, Wijbrandts CA, et al. Surprising negative association between IgG1 allotype disparity and anti-adalimumab formation: a cohort study. Arthritis Res Ther. 2010;12(6):R221. doi:10.1186/ ar3208.

50. Mandy WJ. A new serum factor in normal rabbits. 3. Specificity for antigenic determinants uncovered by papain or pepsin digestion. J Immunol. 1967;99(4):815-24

51. Brezski RJ, Knight DM, Jordan RE. The origins, specificity, and potential biological relevance of human anti-IgG hinge autoantibodies.Scientific World Journal. 2011 May 26;11:115367. doi:10.1100/tsw.2011.107.

52. Curtis BR, Swyers J, Divgi A, McFarland JG, Aster RH. Thrombocytopenia after second exposure to abciximab is caused by antibodies that recognize abciximab-coated platelets.Blood. 2002;99(6):2054-9.

53. Holland MC, Wurthner JU, Morley PJ, Birchler MA, Lambert J, Albayaty M, Serone AP, Wilson R, Chen Y, Forrest RM, Cordy JC, Lipson DA, Bayliffe AI Autoantibodies to variable heavy $(\mathrm{VH})$ chain Ig sequences in humans impact the safety and clinical pharmacology of a VH domain antibody antagonist of TNF- $\alpha$ receptor 1. J Clin Immunol. 2013;33(7):1192-203. doi:10.1007/ s10875-013-9915-0.

54. Papadopoulos KP, Isaacs R, Bilic S, Kentsch K, Huet HA, Hofmann M, Rasco D, Kundamal N, Tang Z, Cooksey J, Mahipal A. Unexpected hepatotoxicity in a phase I study of TAS266, a novel tetravalent agonistic Nanobody® targeting the DR5 receptor. Cancer Chemother Pharmacol. 2015;75(5):887-95. doi:10.1007/s00280-015-2712-0.

55. Webster R, Didier E, Harris P, Siegel N, Stadler J, Tilbury L, et al. PEGylated proteins: evaluation of their safety in the absence of definitive metabolism studies. Drug Metab Disposition: Biol Fate Chem. 2007:35(1):9-16. doi:10.1124/dmd.106.012419.

56. Bell EA, Wall GC. Pediatric constipation therapy using guidelines and polyethylene glycol 3350. Ann Pharmacother. 2004;38(4):686-93. doi:10.1345/aph.1D297.

57. Mehvar R. Modulation of the pharmacokinetics and pharmacodynamics of proteins by polyethylene glycol conjugation. J Pharm Pharm Sci. 2000;3(1):125-36.

58. Kang JS, Deluca PP, Lee KC. Emerging PEGylated drugs. Expert Opin Emerg Drugs. 2009;14(2):363-80. doi:10.1517/ 14728210902907847.

59. Pasut G. Pegylation of biological molecules and potential benefits: pharmacological properties of certolizumab pegol. BioDrugs. 2014;28 Suppl 1:15-23. doi:10.1007/s40259-013-0064-z.

60. Richter AW, Akerblom E. Polyethylene glycol reactive antibodies in man: titer distribution in allergic patients treated with monomethoxy polyethylene glycol modified allergens or placebo, and in healthy blood donors. Int Arch Allergy Appl Immunol. 1984;74(1):36-9.

61. Garay RP, El-Gewely R, Armstrong JK, Garratty G, Richette P. Antibodies against polyethylene glycol in healthy subjects and in patients treated with PEG-conjugated agents. Expert Opin Drug Deliv. 2012;9(11):1319-23. doi:10.1517/17425247.2012.720969.

62. Myler H, Hruska MW, Srinivasan S, Cooney E, Kong G, Dodge $\mathrm{R}$, et al. Anti-PEG antibody bioanalysis: a clinical case study with PEG-IFN-lambda-1a and PEG-IFN-alpha2a in naive patients. Bioanalysis. 2015;7(9):1093-106.

63. Lipsky PE, Calabrese LH, Kavanaugh A, Sundy JS, Wright D, Wolfson M, et al. Pegloticase immunogenicity: the relationship between efficacy and antibody development in patients treated for refractory chronic gout. Arthritis Res Ther. 2014;16(2):R60. doi:10.1186/ar4497.

64. Hershfield MS, Ganson NJ, Kelly SJ, Scarlett EL, Jaggers DA, Sundy JS. Induced and pre-existing anti-polyethylene glycol antibody in a trial of every 3-week dosing of pegloticase for refractory gout, including in organ transplant recipients. Arthritis Res Ther. 2014;16(2):R63. doi:10.1186/ar4500.

65. Armstrong JK, Hempel G, Koling S, Chan LS, Fisher T, Meiselman HJ, et al. Antibody against poly(ethylene glycol) adversely affects PEG-asparaginase therapy in acute lymphoblastic leukemia patients. Cancer. 2007;110(1):103-11. doi:10.1002/cncr.22739.

66. Hu X, Miller L, Richman S, Hitchman S, Glick G, Liu S, et al. A novel PEGylated interferon beta-1a for multiple sclerosis: safety, pharmacology, and biology. J Clin Pharmacol. 2012;52(6):798808. doi:10.1177/0091270011407068.

67. Carter PJ, Senter PD. Antibody-drug conjugates for cancer therapy. Cancer J. 2008;14(3):154-69.

68. Krieckaert C, Rispens T, Wolbink G. Immunogenicity of biological therapeutics: from assay to patient. Curr Opin Rheumatol. 2012;24(3):306-11. doi:10.1097/BOR.0b013e3283521c4e.

69. Maiese WM, Lechevalier MP, Lechevalier HA, Korshalla J, Kuck N, Fantini A, et al. Calicheamicins, a novel family of antitumor antibiotics: taxonomy, fermentation and biological properties. J Antibiot. 1989;42(4):558-63.

70. Wensel DL, Awwad M. Elimination of interference in immunoassays caused by anti-carbohydrate antibodies. USA: Wyeth, John, and Brother Ltd; 2008. p. 60.

71. Carrasco-Triguero M, Yi JH, Dere R, Qiu ZJ, Lei C, Li Y, et al. Immunogenicity assays for antibody-drug conjugates: case study with ado-trastuzumab emtansine. Bioanalysis. 2013;5(9):1007-23. doi:10.4155/bio.13.64.

72. U.S. Food and Drug Administration F. Kadcyla Prescribing Information. Ado-Trastuzumab Emtansine. Drugs @ FDA: FDA; 2013; Available from: http://www.accessdata.fda.gov/ drugsatfda_docs/label/2013/125427lbl.pdf.

73. Mathew M, Verma RS. Humanized immunotoxins: a new generation of immunotoxins for targeted cancer therapy. Cancer Sci. 2009;100(8):1359-65.

74. Foss F. Clinical experience with denileukin diftitox (ONTAK). Semin Oncol. 2006:33(1 Suppl 3):S11-6.

75. Matar AJ, Pathiraja V, Wang Z, Duran-Struuck R, Gusha A, Crepeau $\mathrm{R}$, et al. Effect of pre-existing anti-diphtheria toxin antibodies on $\mathrm{T}$ cell depletion levels following diphtheria toxinbased recombinant anti-monkey CD3 immunotoxin treatment. Transpl Immunol. 2012;27(1):52-4.

76. Frankel AE, Zuckero SL, Mankin AA, Grable M, Mitchell K, Lee YJ, et al. Anti-CD3 recombinant diphtheria immunotoxin therapy of cutaneous $\mathrm{T}$ cell lymphoma. Curr Drug Targets. 2009;10(2):104-9.

77. Watanabe M, Uchida K, Nakagaki K, Trapnell BC, Nakata K. High avidity cytokine autoantibodies in health and disease: pathogenesis and mechanisms. Cytokine Growth Factor Rev. 2010;21(4):263-73.

78. Suzuki H, Akama T, Okane M, Kono I, Matsui Y, Yamane K, et al. Interleukin-1-inhibitory $\operatorname{IgG}$ in sera from some patients with rheumatoid arthritis. Arthritis Rheum. 1989;32(12):1528-38.

79. Browne SK, Holland SM. Anticytokine autoantibodies in infectious diseases: pathogenesis and mechanisms. Lancet Infect Dis. 2010;10(12):875-85.

80. Cousens LP, Mingozzi F, van der Marel S, Su Y, Garman R, Ferreira $\mathrm{V}$, et al. Teaching tolerance: new approaches to enzyme replacement therapy for Pompe disease. Hum Vaccin Immunother. 2012;8(10):1459-64. doi:10.4161/hv.21405.

81. Sun B, Bird A, Young SP, Kishnani PS, Chen YT, Koeberl DD. Enhanced response to enzyme replacement therapy in Pompe disease after the induction of immune tolerance. Am J Hum Genet. 2007;81(5):1042-9. doi:10.1086/522236.

82. Messinger $\mathrm{YH}$, Mendelsohn NJ, Rhead W, Dimmock D, Hershkovitz E, Champion M, et al. Successful immune tolerance induction to enzyme replacement therapy in CRIM-negative infantile Pompe disease. Genet Med : Off J Am Coll Med Genet. 2012;14(1):135-42. doi:10.1038/gim.2011.4.

83. Starzyk K, Richards S, Yee J, Smith SE, Kingma W. The longterm international safety experience of imiglucerase therapy for Gaucher disease. Mol Genet Metab. 2007;90(2):157-63. doi:10.1016/j.ymgme.2006.09.003.

84. Hollak CE, Linthorst GE. Immune response to enzyme replacement therapy in Fabry disease: impact on clinical outcome? Mol Genet Metab. 2009;96(1):1-3. doi:10.1016/j.ymgme.2008.10.013.

85. Cugno M, Gualtierotti R, Tedeschi A, Meroni PL. Autoantibodies to coagulation factors: from pathophysiology to diagnosis and therapy. Autoimmun Rev. 2014;13(1):40-8. doi:10.1016/ j.autrev.2013.08.001. 
86. Manno CS, Pierce GF, Arruda VR, Glader B, Ragni M, Rasko $\mathrm{JJ}$, et al. Successful transduction of liver in hemophilia by AAVFactor IX and limitations imposed by the host immune response.[Erratum appears in Nat Med. 2006 May;12(5):592 Note: Rasko, John [corrected to Rasko, John JE]; Rustagi, Pradip K [added]]. Nat Med. 2006;12(3):342-7.

87. Maclachlan TK, Lukason M, Collins M, Munger R, Isenberger E, Rogers C, et al. Preclinical safety evaluation of AAV2sFLT01- a gene therapy for age-related macular degeneration. Mol Ther: J Am Soc Gene Ther. 2011;19(2):326-34.

88. Creager MA, Olin JW, Belch JJ, Moneta GL, Henry TD, Rajagopalan S, et al. Effect of hypoxia-inducible factor-1alpha gene therapy on walking performance in patients with intermittent claudication. Circulation. 2011;124(16):1765-73.

89. Annoni A, Cantore A, Della Valle P, Goudy K, Akbarpour M, Russo F, et al. Liver gene therapy by lentiviral vectors reverses anti-factor IX pre-existing immunity in haemophilic mice. EMBO Mol Med. 2013;5(11):1684-97.

90. Louis Jeune V, Joergensen JA, Hajjar RJ, Weber T. Pre-existing anti-adeno-associated virus antibodies as a challenge in AAV gene therapy. Hum Gene Ther Part B Methods. 2013;24(2):5967.

91. Orlova NA, Kovnir SV, Vorobiev II, Gabibov AG. Coagulation factor IX for hemophilia B therapy. Acta Nat. 2012;4(2):62-73.

92. Calcedo R, Vandenberghe LH, Gao G, Lin J, Wilson JM. Worldwide epidemiology of neutralizing antibodies to adenoassociated viruses. J Infect Dis. 2009;199(3):381-90.
93. Erles K, Sebokova P, Schlehofer JR. Update on the prevalence of serum antibodies (IgG and $\mathrm{IgM}$ ) to adeno-associated virus (AAV). J Med Virol. 1999;59(3):406-11.

94. Parks WP, Boucher DW, Melnick JL, Taber LH, Yow MD. Seroepidemiological and ecological studies of the adenovirus-associated satellite viruses. Infect Immun. 1970;2(6):716-22.

95. Blacklow NR, Hoggan MD, Rowe WP. Serologic evidence for human infection with adenovirus-associated viruses. J Natl Cancer Inst. 1968;40(2):319-27.

96. Wang L, Calcedo R, Bell P, Lin J, Grant RL, Siegel DL, et al. Impact of pre-existing immunity on gene transfer to nonhuman primate liver with adeno-associated virus 8 vectors. Hum Gene Ther. 2011;22(11):1389-401.

97. Jaski BE, Jessup ML, Mancini DM, Cappola TP, Pauly DF, Greenberg B, et al. Calcium upregulation by percutaneous administration of gene therapy in cardiac disease (CUPID Trial), a first-in-human phase $1 / 2$ clinical trial. J Card Fail. 2009;15(3):171-81.

98. McElrath MJ, De Rosa SC, Moodie Z, Dubey S, Kierstead L, Janes $\mathrm{H}$, et al. HIV-1 vaccine-induced immunity in the test-ofconcept Step Study: a case-cohort analysis. Lancet. 2008;372(9653):1894-905.

99. Liu Q, Huang W, Zhang H, Wang Y, Zhao J, Song A, et al. Neutralizing antibodies against AAV2, AAV5 and AAV8 in healthy and HIV-1-infected subjects in China: implications for gene therapy using AAV vectors. Gene Ther. 2014;21(8):732-8. doi:10.1038/gt.2014.47. 